\title{
EVALUATION OF PATIENT SATISFACTION AND PROSTHETIC MAINTENANCE OF FIXED DETACHABLE PROSTHESIS USED AS TREATMENT MODALITY IN COMPLETELY EDENTULOUS PATIENT
}

\author{
Ahmed Yahia Mohamed Abd El_Wahab* , Ahmed Gamal Ahmed* and Emad Mohammed Tolba*
}

\begin{abstract}
Purpose: The aim of this study was to compare patient satisfaction and prosthetic maintenance of fixed detachable prosthesis and conventional complete dentures.

Materials and method: Eight completely edentulous patients received complete dentures for six months (Group I), then fixed detachable prostheses on four implants for the following six months (GroupII). For both designs, patient satisfaction using visual analogue scale (VAS) and prosthetic maintenance were evaluated.
\end{abstract}

Results: Results of patient satisfaction parameters for group II were significantly higher than group I for retention, mastication and metallic taste. For aesthetics and hygiene, grouplI showed better results than group II. However the difference was insignificant. Regarding prosthetic maintenance, the overall maintenance and service required for group I was greater than group II. Regarding base fracture, relining and occlusal adjustment, more service was needed for group I than group II. Hyperplasia under metal framework and around the abutment was more counted in group II. Excessive wear of the teeth was equally seen in both groups. However, in both groups, the other parameters required no maintenance.

Conclusion: All patients included in this study were satisfied by both designs. However, more satisfaction was recorded by VAS for comfort, speech, retention and mastication in patients wearing fixed detachable prostheses. Regarding prosthetic maintenance, slightly more maintenance was required for conventional complete dentures.

\section{INTRODUCTION}

Rehabilitation of edentulous patients includes a large variety of opinions. The conventional method for treating full edentulism is to provide complete dentures. The diversity of problems caused by complete dentures is not a modern issue. Patients do not only complain about insufficient chewing abilities and articulation problems, but also experience psychic and social impairment (Albaker, 2013).

To overcome these problems, implants have been increasingly used to retain complete dentures

* Lecturer of Prosthodontics, Faculty of Dentistry, Minia University 
and have demonstrated to be a successful treatment alternative (Fueki et al., 2007, Rashid et al., 2011, Barao et al., 2013).

Clinical studies investigating the potential impact of implant-supported prostheses on the oral healthrelated quality of life showed clear improvement after implants had been inserted (Zitzmann \& Marinello 2000a; Allen \& McMillan 2003; Scala et al. 2012; Zembic \& Wismeijer 2014). Nowadays, the insertion and/or restoration of dental implants in edentulous jaws can be considered one of the basic treatment modalities.

One of the preferred prosthetic options for edentulous cases is the fixed detachable prostheses. They consist of metallic framework covered with complete denture that is screwed to inter foraminal or premaxillary implants.

Although fixed detachable prostheses offer psychological and functional advantages over removable dentures, problems as periimplantitis, plaque accumulation and mucositis affect the oral heath related quality of life.

Recently, the effects of different prosthetic options on oral health- related quality of life had great interest. Several indicators have been used for measuring patient satisfaction of oral prosthesis. New conventional complete dentures were believed to produce marked improvements in chewing comfort, chewing ability, eating enjoyment, food choices, security and speech (Garrett et al. 1996; Bouma et al. 1997; Kapur et al. 1998; Allen et al. 2006).

Although fixed detachable prostheses are of greater demand than removable prostheses, they possess aesthetic and biomechanical deficiencies that impair patient satisfaction. The great expectations of the patients may not be met in cases of fixed detachable prostheses leading to poor satisfaction (Preciado et al., 2013).

This study was conducted to compare patient satisfaction and prosthetic maintenance of fixed detachable prostheses and conventional complete dentures.

\section{MATERIALS AND METHOD}

Eight completely edentulous patients were selected from the outpatient clinic, department of prosthodontics, faculty of dentistry, Minia university according to the following criteria:

1- Wearing complete dentures.

2- Good health conditions as follows:

-No diabetes

-No bisphosphonates

-No irradiation or chemotherapy

-No cardiac or haemorrhagic problems

3- Age between 50 and 65 years

4- Bone height and width can accommodate four implants of minimum length of $12 \mathrm{~mm}$ and diameter of $3.75 \mathrm{~mm}$.

5- Normal maxillo-mandibular relationship.

6- Good inter arch distance.

For all patients conventional upper and lower complete denture were constructed, delivered and inspected (Group I). Post insertion adjustments and tratment of any complaint was performed for each patient.

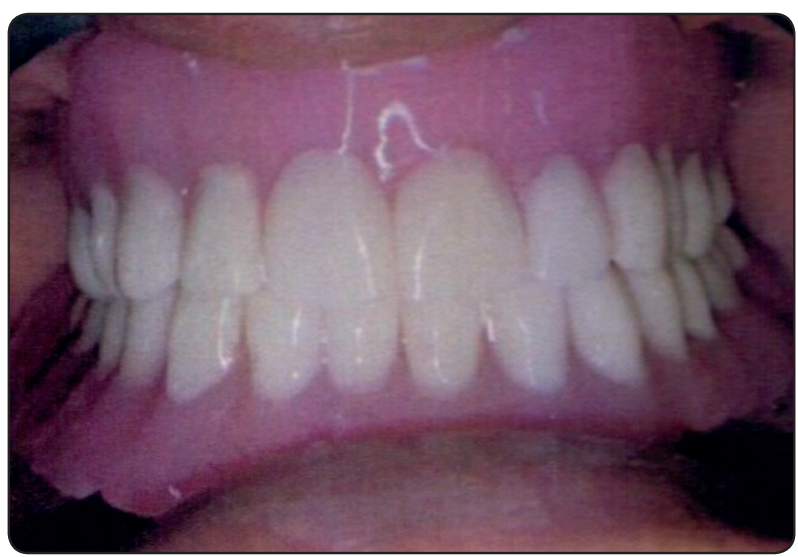

Fig. (1) Conventional complete dentures 
During a six months period after insertion, patients were recalled every three months to evaluate patient satisfaction and every month to evaluate prosthetic maintenance.

After six months, all patient were recalled to receive an implant supported fixed detachable prostheses (Group II).

Cone beam scan was made for each patient to determine the exact implant length, width and location.

Under local anaesthesia, flap was reflected and four implants (s-clean.tapered dental implant fixture-Dentis-Korea) $3.75 \mathrm{~mm}$ in diameter and $12 \mathrm{~mm}$ in length were installed in the anterior region with the aid of surgical stent.

During the healing period (three months), patients were instructed to use their old dentures relined with soft liner.

After the healing period, implants were exposed and healing collars were attached.

Impressions were made, poured and master casts were obtained.

The obtained casts were modified and duplicated into refractory casts.

On the refractory cast, waxing up of the metal framework was built up. The undersurface of the final waxed up metal framework was made rounded

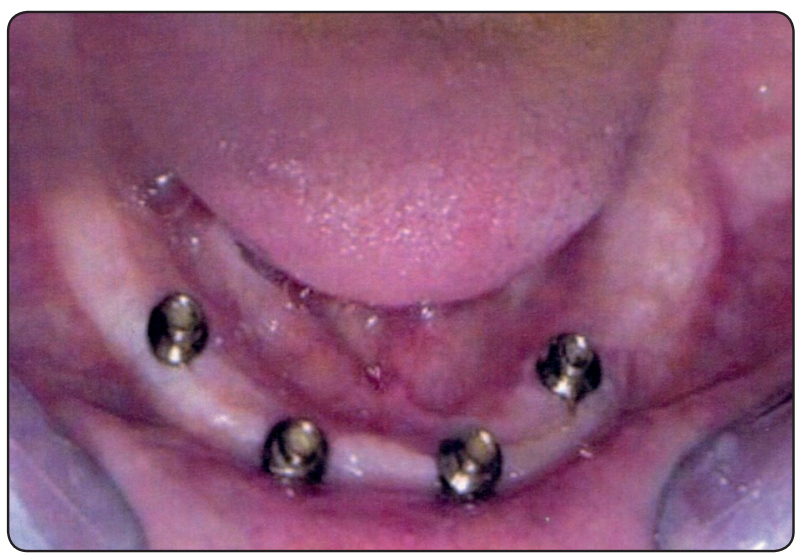

Fig. (2) Four implants for fixed detachable prostheis and two millimeters away from crest of the ridge. Two cantilever arms were extended distally from the wax pattern on both sides. The wax pattern was sprued, invested and cast into cobalt chromium alloy. The obtained metal framework was inpected and checked for passivity using single screw test where any gaps or difficulty in seating means lack of passivity.

The framework was then sandblasted and painted with a bonding agent.

On the master cast, lower trial denture base was constructed and wax rims attached for recording centic jaw relation and occlusal verical dimension. After checking the jaw relation, occlusion blocks were mounted on a semiadjustable articulator using maxillary face bow records.

The trial denture bases were then extended to be aesthetically accepted. Labial and buccal flanges were extended only few millimeters above the crest of the ridge. Posteriorly, the base was extended only few millimeters over the residual ridge leaving the retromolar pad area uncovered.

Artificial cross linked acrylic modified anatomic teeth were the set up according to the lingualized occlusal concept.

Waxed up dentures were then checked inside patient mouth for extension, esthetics, phonetics and satisfaction before they sent to the laboratory for prosthesis fabrication.

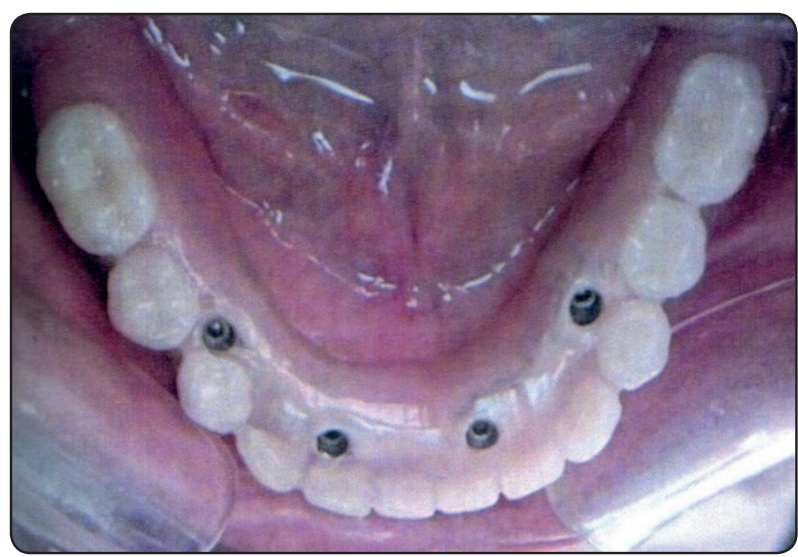

Fig. (3) Fixed detachable prostheis screwed intraorally 
Final prostheses were screwed intraorally using torque wrench. Occlusion was then checked and any premature contact or interference was removed.

The four access holes were plugged with rubber piece and closed with composite.

All patients were instructed to use soft brushes and interdental brushes to remove food debris under the prostheses and between implants.

As for group I, patients were allowed to wear their prostheses for six months. During this period patients were recalled every three months to evaluate patient satisfaction and every month to evaluate prosthetic maintenance.

\section{Method of evaluation of patient satisfaction:}

Visual Analougue Scale (VAS) eight item questionnaire was used.

The questionnaire included:

1. Overall satisfaction

2. Comfort of wearing dentures

3. Speech and phonation

4. Chewing ability

5. Metallic taste

6. Stability and retention of mandibular dentures

7. Handling of the dentures(insertion and removal)

8. Ease of hygiene procedure

The answers of the patient were recorded by means of VAS of $100 \mathrm{~mm}$. every three months for both groups.

\section{Method of evaluation of prosthetic Maintenance:}

The following 9 items were evaluated and recorded evey month for both groups.

1- Denture base fracture

2- Fracture or loss of teeth

3- Fracture of cast framwork
4- Change of denture design

5- Hyperplasia under metal framework

6- Relining of the denture

7- Occlusal adjustment of the denture

8- Excessive wear of teeth

9- Hyperplasia around abutment

The SPSS statistical package (SPSS Inc., Chicago, IL, USA) was used for statistical analysis. For VAS questionnaire, the Wilcoxon test was used.

\section{RESULTS}

More overall satisfaction was recorded by VAS in group II. The results of patient satisfaction parameters for group II were significantly higher than group I for retention, mastication and metallic taste. For aesthetics and ease of hygiene procedures, grouplI showed better results than group II. However the difference was insignificant.

TABLE (1) Mean values and standard deviation of VAS parameters

\begin{tabular}{|l|c|c|l|}
\hline \multicolumn{1}{|c|}{ VAS parameters } & $\begin{array}{c}\text { Group I } \\
\text { Mean } \pm \text { SD }\end{array}$ & $\begin{array}{c}\text { Group II } \\
\text { Mean } \pm \text { SD }\end{array}$ & P value \\
\hline Overall Satisfaction & $87 \pm 1.29$ & $90 \pm 1.29$ & $\mathrm{P}>0.05$ \\
\hline Comfort & $90 \pm 1.29$ & $92 \pm 0.97$ & $\mathrm{P}>0.05$ \\
\hline Speech & $90 \pm 1.29$ & $91 \pm 1.41$ & $\mathrm{P}>0.05$ \\
\hline Retention & $81 \pm 0.97$ & $92 \pm 1.41$ & $\mathrm{P}<0.05^{*}$ \\
\hline Esthetics & $91 \pm 1.25$ & $90 \pm 0.97$ & $\mathrm{P}>0.05$ \\
\hline Mastication & $82 \pm 1.34$ & $91 \pm 1.52$ & $\mathrm{P}<0.05^{*}$ \\
\hline Metallic taste & $80 \pm 5.45$ & $92 \pm 1.41$ & $\mathrm{P}<0.05^{*}$ \\
\hline Hygiene & $90 \pm 1.86$ & $88 \pm 1.60$ & $\mathrm{P}>0.05$ \\
\hline
\end{tabular}

Group I conventional complete dentures

Group II fixed detachable prostheses

$* P<0.05$ indicates significant difference 


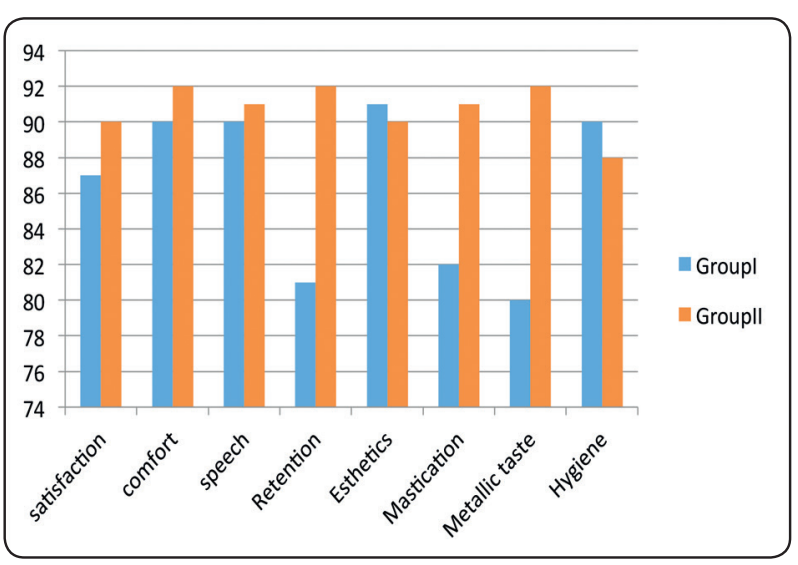

Fig. (4) Graph showing the mean values of VAS parameters

Regarding prosthetic maintenance, the overall maintenance and service required for group I was greater than group II. Regarding base fracture, relining and occlusal adjustment, more service was needed for group I than group II. Hyperplasia under metal framework and around the abutment was more counted in group II. Excessive wear of the teeth was equally seen in both groups. However, in both groups, the other parameters required no maintenance.

TABLE (2) Prosthetic Maintenance and service

\begin{tabular}{|l|c|c|}
\hline Prosthetic Maintenance & Group I & Group II \\
\hline 1. denture base fracture & 1 & 0 \\
\hline 2. fracture / loss of teeth & 0 & 0 \\
\hline 3. fracture of frame work & 0 & 0 \\
\hline 4. change of denture design & 0 & 0 \\
\hline $\begin{array}{l}\text { 5. hyperplasia under metal frame } \\
\text { work }\end{array}$ & 0 & 1 \\
\hline 6- relining of denture & 1 & 0 \\
\hline $\begin{array}{l}\text { 7- occlusal adjustment of the } \\
\text { denture }\end{array}$ & 3 & 1 \\
\hline 8-Excessive wear of the teeth & 1 & 1 \\
\hline 9-hyperplasia around the abutment & 0 & 1 \\
\hline Total & 6 & 4 \\
\hline
\end{tabular}

\section{DISUSSION}

All the patients included in this study fulfilled the inclusion criteria.

Patients were systemic free and had enough bone height, width, and quality to ensure implant success.

To accommodate the height of fixed detachable prostheses, only patients with sufficient inter-arch distance were selected.

All the successful criteria for denture construction were followed; ideal impressions, accurate jaw relation, try-in then finally denture insertion with occlusal adjustment.

All the patients were recalled two days after denture insertion for relieving any patient complaint.

A period of denture adaptation about three weeks was allowed to allow for denture settling.

All the patients were trained about oral and denture hygiene.

All the patients were satisfied with their dentures through-out the whole follow-up period. The second design with fixed detachable prostheses showed an overall patient satisfaction more than that of conventional complete denture but without significance. This may be attributed to the increase gained in retention and stability of the prostheses.

Regarding the comfort of patients, most of the patients revealed that the screw-retained prostheses are more comfortable than that of conventional dentures. This can be due to changing the case from tissue supported with its complications into a case with totally implant supported prostheses which cancelled all the tissue problems from sore spots and traumatization. Meanwhile, the results revealed that there was no significant difference regarding the patient comfort.

According to the data obtained, patients reported improvement in speech and phonetics with fixed detachable design. This may be due to the better quality of retention in this design. 
From the VAS questionnaire chart, retention was dramatically improved in the second group with significant difference. This obvious change was due to changing the type of retention from mainly a physical retention in group I into a mechanical method of retention using the tightening screws in group II.

Esthetically, all the patients were more satisfied with their conventional dentures than fixed detachable prostheses. This is attributed to the short labial flange in the second design which impairs labial support and exposes the space under the prosthesis.

Regarding the mastication, all the patients were highly satisfied with the new design of screw retained one and this can be attributed to the stable basal foundation and stable occlusal contacts that enable the patients to masticate properly. Consequently, this can be revealed by the collected data that showed high significance between the two designs.

For the feeling of a metallic taste, the collected data revealed that most of the patients complain from the metallic taste was detected in the screw retained design which is related to the metallic framework.

Regarding ease of hygiene procedures, patients experienced easier cleaning procedures in the conventional design. This is due to the complicated design of the screw retained prostheses, which permits only cleaning of the relief area underneath the prostheses using interdental brushes.

Fracture of denture base was registered in one case with the conventional design. No fracture base encountered in the fixed detachable design due to the presence of metal framework.

Hyperplasia under the denture and around abutment was only seen in the fixed detachable design which is attributed to proliferation of mucosa in the gap under the framework together with difficulty of cleaning and lack of tissue massage.

Three cases with conventional dentures required relining versus only one case with fixed detachable design. This is due to the better quality of retention and support in the second design which leads to less stresses on the basal structures and less bone desorption compared to conventional design.

More occlusal adjustment was needed for conventional dentures. These dentures are totally tissue supported. Resiliency of the mucosa and settling together with movement of the prostheses and accelerated bone resorption are responsible for the more occlusal adjustments required in conventional cases.

\section{CONCLUSION}

Within limitations of this study, the following can be concluded:

All patients included in this study were satisfied by conventional dentures as well as fixed detachable prostheses. However, more satisfaction was recorded by VAS for comfort, speech, retention and mastication in patients wearing fixed detachable prostheses. Regarding prosthetic maintenance, slightly more maintenance was required for conventional complete dentures.

\section{REFERENCES}

1. Albaker AM. The oral health-related quality of life in edentulous patients treated with conventional complete dentures. Gerodontology 2013, 30:61-66.

2. Fueki K, Kimoto K, Ogawa T, Garrett NR. Effect of implant-supported or retained dentures on masticatory performance: asystematic review. Journal of Prosthetic Dentistry $2007,98(6), 470-477$.

3. Rashid F, Awad MA, Thomason JM, Piovano A, Spielberg GP, Scilingo E, Mojon P, Muller F, Spielberg M, Heydecke G, Stoker G,Wismeijer D, Allen F, Feine JS. The effectiveness of 2-implant overdentures- apragmatic international multicenter study. Journal of Oral Rehabilitation 2011, 38(3), 176-184.

4. BaraoVAR, Delben JA, Lima J, Cabral T, Assuncao WG, Comparisonof different designs of implant-retained overdentures and fixed full-arch implant- supported prosthesis 
on stress distribution in edentulous mandible-A computed tomography-based three-dimensional finite element analysis. Journal of Biomechanics 2013, 46(7),1312-1320.

5. Zitzmann NU \& Marinello CP. Treatment outcomes of fixed or removable implant supported prostheses in the edentulous maxilla. Part I: patients' assessments. Journal of Prosthetic Dentistry 2000a, 83: 424-433.

6. Allen PF, McMillan AS. A longitudinal study of quality of life outcomes in older adults requesting implant prostheses and complete removable dentures. Clinical Oral Implants Research 2003;14:173-9.

7. Scala R, Cucchi A, Ghensi P \& Vartolo F. Clinical evaluation of satisfaction in patients rehabilitated with an immediately loaded implant-supported prosthesis: a controlled prospective study. The International Journal of Oral and Maxillofacial Implants 2012, 27:911-919.

8. Zembic A\& Wismeijer D. Patient-reported outcomes of maxillary implant-supported overdentures compared with conventional dentures. Clinical Oral Implants Research 2014, 25: 441-450.

9. Garrett NR, Kapur KK \& Perez P. Effects of improvements of poorly fitting dentures and new dentures on patient satisfaction. Journal of Prosthetic Dentistry 1996, 76: 403-413.

10. Bouma J, Boerrigter, LM, van Oort RP, van Sonderen E \& Boering G. Psychosocial effects of implant-retained overdentures. International Journal of Oral \& Maxillofacial Implants 1997,12: 515-522.

11. Kapur KK, Garrett NR, Hamada MO, Roumanas ED, Freymiller E, Han T, Diener RM, Levin S \& Ida R. A randomized clinical trial comparing the efficacy of mandibular implant-supported overdentures and conventional dentures in diabetic patients. Part I: Methodology and clinical outcomes. Journal of Prosthetic Dentistry1998, 79: 555-569.

12. Allen PF, Thomason JM, Jepson NJ, Nohl F, Smith DG \& Ellis J. A randomized controlled trial of implant-retained mandibular overdentures. Journal of Dental Research 2006, 85: 547-551.

13. Arelis Preciado a, Jaime Del Rióo a, Christopher D. Lynch b, Raquel Castillo-Oyagu" e a. Impact of various screwed implant prostheses on oral health-related quality of life as measured with the QoLIP-10 and OHIP-14 scales: A cross-sectional study. Journal of Dentistry 2013, 41:1196-1207 